\title{
Article
}

\section{Ying $\mathrm{Xu}^{*}$}

\section{Volunteer Participation and the Development of Civil Society in China: A Case Study of Jinan}

\begin{abstract}
Spontaneous volunteer participation has developed rapidly over the past decade, though compulsory volunteer participation through top-to-bottom, government-based organizations is still prevalent among Chinese citizens. Drawing on a case study of Jinan, a city in China, this study explores the types of and motives for volunteer participation including how volunteers differ in their voluntary service experiences and what their attitudes are toward volunteering and the future development of civil society in China. The findings illustrate: first, spontaneous participants with rewarding experiences who volunteer through grassroots, issue-based VSOs are most likely to have a positive attitude toward volunteering and believe that volunteering can make contributions to the development of civil society. Second, participants in grassroots and community-based VSOs are most likely to have an enthusiastic attitude toward volunteering, but they tend to be indifferent about the idea of civil society. However, they tend to contribute to the development of volunteering and civil society when given the opportunity, because participation in voluntary services enhances their participatory abilities and their sense of self-organization and mutual collaboration. Last but not least, volunteers who participate in a poorly managed volunteering organization and have a dissatisfactory, non-rewarding volunteering experience are most likely to have a pessimistic attitude toward volunteering and civil society. The implications of volunteering for the development of civil society are also discussed.
\end{abstract}

Keywords: volunteering, volunteer participation, civil society, voluntary service organization, non-governmental organization

*Corresponding author: Ying Xu, Department of Social Work, The Chinese University of Hong Kong, Hong Kong, China, E-mail: helloyingxu@gmail.com

\section{Introduction}

Formal volunteering is a process in which an individual chooses to act through an organization in recognition of a need and without concern for monetary profit 
(Cnaan, Femida and Margaret 1996; Bekkers 2008). In socialist China, formal volunteering only began to appear in the mid-1990s when the government endorsed the "socialization of social welfare" policy (Tian 2004). It is estimated that the volunteer rate in Chinese cities is about 3\% (Pan 2005). Compared to the average rate of about $20-40 \%$ in developed countries, China's volunteering rate is very low (Anheier and Salamon 1999; U.S. Bureau of Labor Statistics 2009; Taniguchi 2010). To encourage people to volunteer, the Chinese government has organized various activities (e.g., Chinese Youth Volunteers Movement, Graduates Volunteering in Western China, etc.) at both local and national levels since the 1990s (Xu 2012a, 2012c).

Volunteers in Western countries have played an important role in shaping a functioning civil society since the seventeenth century by enhancing public participation, which helps people who might not otherwise be involved in politics to pursue freedom and social justice (Walter and Dimaggio 1983; Heiderich 1990; White, Howell, and Shang 1996). In applying Anheier's (2004) Civil Society Index (CSI) for assessment, however, Jia and Pan (2006) found that the structure and macro-environment of civil society - such as the intensity of citizen participation, the development and cooperation of voluntary organizations, the presence of international links, the resources, and the legal environment - are obviously weak in China.

Thus, the potential contributions of volunteers toward promoting the development of civil society in China deserve a specific investigation. The qualitative method was used to conduct a case study of the city of Jinan, with the following objectives: (1) to explore the main types of voluntary services, (2) to describe how volunteers perceive their volunteering experiences, and (3) to discuss how volunteering experiences affect the volunteers' attitudes toward the act of volunteering and the development of civil society.

\section{Theoretical discourses and the Chinese context}

There is no real consensus among scholars regarding the relationships between volunteering and civil society, although there are basic civic values and core elements that have brought scholars together to develop theoretical discourses (Arendt 1958; Habermas 1989; Cohen and Arato 1992; Young 2000). First, at the macro-ideological level, some scholars believe that volunteering is one of the fundamental building blocks of civil society, because voluntary actions and civil society share basic civic values such as altruism, public participation, and autonomy 
(IAVE 2001). In other words, volunteering can contribute to the development of civil society, which itself addresses "the sphere of voluntary action between the market and state" that may foster civic values (Heinrich 2004, 1). Meanwhile, from a cultural-ideological perspective, others argue that both volunteering and civil society are Western concepts. Thus, it would be impossible to build a Westernstyle civil society in China (Deng and Jing 1992). Moreover, Jiang (1993) advocates the development of a Chinese-style civil society based on Confucianism that emphasizes a society ruled by an elite class that provides limited freedom and equality to the masses with a reasonable degree of hierarchy.

Second, at the meso-institutional level, Taylor (1995) argued that a society can be regarded as a civil society when it can spontaneously organize voluntary services "that are not under tutelage of state power" (p. 208). The reasoning for this is that a non-political volunteer group is more likely to be an enclave that enjoys autonomy, while other social organizations (e.g., religious or political associations) remain under systemic pressure (Xu and Ngai 2011). In a relatively conservative, non-Western society, volunteers are more likely to be active participants serving the public good to foster a sense of civil society (Trentmann 2000). With respect to the diversity of organizations, however, scholars have also argued that not all voluntary services enhance an individual's sense of social responsibility or promote the development of civil society. This is thought to be the case, because some volunteer groups might emphasize the economic, religious, or ethical interests of specific interest groups, pressure groups, or professional organizations - further dividing the society (Geller 1996; Barber 1998; Wagner 2004).

Third, from a micro-individual perspective, many studies reveal that volunteers might contribute to the development of civil society because their service participation facilitates the integration of volunteers with the social-institutional sphere, enhancing the self-assurance and self-efficacy that helps them to become responsible citizens (NaKano 2000; Cheung and Ngai 2004; McFarland and Thomas 2006; Ngai et al. 2008; Pick, Holmes, and Brueckner 2011). However, some studies have also indicated that volunteering is not necessarily a positive causal factor in the development of civil society at the micro-individual level. The results of many surveys reveal that the outcomes of volunteering can be influenced positively as well as negatively by the management styles and specific participatory experiences of each volunteer (Ellis 1986; McCurley and Lynch 2006; Hager and Brudney 2008; Brudney and Meijs 2009; Eisner et al. 2009; Hustinx 2010). For example, the problematic management of volunteers in hierarchical relationships and the lack of support and autonomy might discourage volunteers' enthusiasm and reduce their potential to become active citizens (Milligan and Fyfe 2005; Adams 2006). 
Indeed, the connections between volunteer participation and the development of civil society are complex. An understanding of indigenous factors and the social context are necessary for the success of studies that focus on volunteering and civil society in non-Western countries such as China. Historically, China features a centralized political tradition that is very different from the modern liberal Western traditions in which voluntary service organizations emerge spontaneously to address issues related to helping the poor in industrialized societies. Traditional Chinese Confucians believe that the government should be the primary welfare provider. In the early days of Communist China, the government also criticized charity as "a fraudulent instrument of imperialism," and banned grassroots voluntary organizations (Tian 2004). However, the opening-up policy has begun to create opportunities for non-political grassroots associations to offer services to the poor or aggrieved since the late 1990s (Tian 2004; Kennedy 2008). Thus, in theory, the state has drawn on a variety of opportunities for promoting volunteering: from mandated forms of participation through government-organized organizations to spontaneous volunteering via grassroots associations. Optimists believe that the development of grassroots associations and spontaneous volunteering could potentially emerge as a generational process that helps to promote civil society in China (Watson 2008). Nevertheless, because most of the major associations in China are founded and supported by the state and remain under the control of the agencies of the Chinese Communist Party (CCP) (Unger and Chan 2008), scholars also argued that it is not uncommon for the government-organized organizations to use local communities as a means of implementing policies or distributing resources rather than to promote active citizenship or civil society (Srinivas 2009).

Moreover, researchers have found that top-to-bottom projects are less likely to satisfy the original goals of volunteer promotion (Brudney and Meijs 2009). For instance, Wang (2003) observed that "people's willingness to participate in services and the moral values of the voluntary service are under the shadow of the organizational power...The volunteers...lack... internal motivation and the ability to participate in the services positively, actively, creatively... Even though they have participated in the services, they are blind and passive" (p. 23). Tan (2001) also noted that "the motives of the volunteers have little effect on the service organizations; on the contrary, the environment of the organization has [a] significant impact on the volunteers' motivation during the voluntary services” (p. 55).

Taken together, these studies of the links between volunteers, civil society, and the socio-political context suggest that the connections between volunteering and the development of civil society in China quickly become more complex than the theoretical discourses based on the history of Western countries. 


\section{Method}

\section{The research site}

This study applies qualitative methods by using semi-structured, in-depth interviews to collect data in Jinan, which is the capital of Shandong Province and one of China's “National Heritage Cities.” This research site was chosen for two main reasons. First, the Jinan Municipal Government responded positively to the call of the Central Committee of the Communist Youth League (CYL) and started the "Youth Volunteer Movement" in the early 1990s (Jinan Daily 2009). It was the first city to legislate volunteering in Shandong Province by promulgating the Jinan Volunteering Administration Regulations on October 1, 2006 (Jinan Development and Reform Commission 2006). Second, Jinan is a Chinese “Middletown" (Lynd and Lynd 1929), which is considered to be more representative of Chinese cities than metropolises such as Beijing, Shanghai, and Tianjin. Jinan has most of the characteristics of contemporary Chinese cities, such as the average population size and a less-developed economy and technology.

\section{Sampling, data collection, and analysis}

A total of 30 interviewees participated in the study. The data have two parts. (1) The interview data draw from a case study undertaken in Jinan between 2006 and 2008, including 3 officials, 6 organizers, and 20 volunteers of the voluntary service organizations (VSOs) (Xu 2012b; Xu and Ngai 2011). (2) The data which were collected during a follow-up field trip in Jinan and Beijing in July 2012 through a second interview with the organizer of VSO-C and a volunteer from VSO-D in Jinan and a new interview with the director of the Department of Youth Volunteer Work of the Central CYL, who is in charge of the national annual project "Graduates Volunteering in Western China" (GVWC) in Beijing.

The study applied a stratified purposive sampling strategy to select the VSOs and organizers, snowball sampling to select the volunteers, and purposive sampling to select the officials. The stratified purposive sampling process included an extensive review of local newspapers and websites to collect information on 34 VSOs in Jinan, such as their organizational missions and latest activities. Based on a two-dimensional coordinating system, which classified the VSOs into four quadrants (i.e., issue-based grassroots VSOs, issue-based (quasi-) governmental-organized VSOs, community-based grassroots VSOs, and 
community-based (quasi-)governmental-organized VSOs), ${ }^{1}$ a total of six VSOs were selected for the study (see Table 2 in Appendix, see also Xu and Ngai 2011). One senior organizer from each VSO was chosen to participate in the interviews. Internal publications and the reports regarding the VSOs were also collected.

A total of 20 volunteers were selected through snowball sampling: each organizer was asked at the end of the interview to recommend three to four core volunteers who have actively participated in the VSO's volunteering activities. The volunteers have 1 to 9 years voluntary service experience (see Table 3 in Appendix).

Through a purposive sampling, three officials in Jinan and one official in Beijing who were in charge of the volunteering programs at the community, city, provincial, or national level were interviewed. Each interviewee was interviewed face-to-face at least once.

All the interviews were audio-taped with the interviewees' consent. Communication between the author and the interviewees also continued via phone or email to clarify the accuracy of the interview data and to gain a better understanding of the recent development of volunteering in China. The transcription was made with word-by-word accuracy. The qualitative data analysis software Nvivo 9.0 was applied to assist the data analysis.

\section{Findings}

The findings reveal first, as summarized in Table 1, that there are two major categories of volunteer participation for voluntary service in China: compulsory and spontaneous. Second, the spontaneous volunteers are more likely to have rewarding experiences and have positive attitudes toward volunteering and civil society. In other words, all three compulsory participants from the governmentorganized non-governmental organization (GONGO) VSO-A, who had gained non-rewarding volunteering experience, were pessimistic toward volunteering

1 According to Pickert (2003), community-based voluntary service organizations have three features: (1) members are limited to a certain local geographic area (e.g., a neighborhood or a school district); (2) the organization engages in a wide range of services for the people who live in that district; and (3) the organization has a relatively close connection with local government with the aim of community development. Issue-based organizations also have three main characteristics: (1) the membership comes from a larger geographical area (e.g., from a city, a nation, or even the whole world); (2) the organization engages in a relatively specific set of activities according to its particular mission (e.g., environmental protection, medical aid, legal rights); and (3) the organization usually has a more distant, contract-based relationship with the governments (see also Xu and Ngai 2011). 
and civil society, while 17 spontaneous participants from VSO-B, C, D, E, and F reported that they had rewarding volunteering experiences. Among the spontaneous volunteers, 10 participants who volunteer through the grassroots, issuebased VSO-B, C, and D have positive attitudes toward both volunteering and civil society; and seven volunteers from the grassroots and community-based VSO-F and E were enthusiastic about volunteering but felt indifferent toward civil society. The following sections will elaborate these findings.

Table 1: Types of volunteer participation, volunteering experiences, and volunteers' attitudes toward volunteering and civil society

\begin{tabular}{llll}
\hline Types of participation & $\begin{array}{l}\text { Volunteering } \\
\text { experience }\end{array}$ & Attitudes \\
\cline { 3 - 4 } & & $\begin{array}{l}\text { Toward } \\
\text { volunteering }\end{array}$ & $\begin{array}{l}\text { Toward civil } \\
\text { society }\end{array}$ \\
\hline Compulsory participation (3) & Rewarding (0) & Nil & Nil \\
& Non-rewarding (3) & Pessimistic (3) & Pessimistic (3) \\
Spontaneous & Rewarding (17) & Positive (10) & Positive (10) \\
participation (17) & Non-rewarding (1) & Nil & Nil \\
\hline
\end{tabular}

\section{Two types of volunteer participation: compulsory and spontaneous}

Usually, voluntary service is undertaken freely (Dunn 1995). However, according to the data, both compulsory and spontaneous volunteer participation are common in China. Compulsory participation is a top-to-bottom volunteering approach organized by the government, the CCP, or party-like organizations (e.g., the CYL). People volunteer in response to the government or the CCP's mobilization and request. Spontaneous participation is a bottom-up volunteering approach often initiated by grassroots VSOs. In situations of spontaneous participation, people volunteer for various personal reasons such as filling idle time, helping others, and trying something different.

2 One volunteer, who has joined both the quasi-governmental VSO-B and the grassroots VSO-C, reported that the volunteering experience in $V S O-B$ was non-rewarding, yet the experience in VSO-C is rewarding. 


\section{Compulsory participation in volunteering}

The government-led service program is neither new nor originated in China. For example, the U.S. government leads the Peace Corps, which aims to encourage college students to serve their country in the cause of peace by living and working in developing countries (Gerdes 2011). Promoting volunteering may not only help government officials earn moral superiority but also improve their record of achievement (Xu 2012a). Nevertheless, Chinese people are more likely to volunteer under pressure than the citizens in democratic countries. Because each individual has a personal file (dang an) managed by the personnel department under the CCP committee, s/he may earn a better political record in her/his file if s/he actively participates in the government-organized volunteering, and it may lead to a bad record if $\mathrm{s} / \mathrm{he}$ refuses to respond to the call on volunteerism by the government.

For instance, Mr. Chen expressed that he was pressured to volunteer for the annual project GVWC in 2005, which is jointly organized by the Central Committee of the CYL, the Ministry of Education, the Ministry of Finance and the Ministry of Personnel:

I achieved outstanding school performance. I joined the [Chinese Communist] Party earlier than my classmates in the university. I was the class monitor for four consecutive years, and I had been the Chairman of the Student Union. The University organized some mobilization activities and asked me to go to Xinjiang (an autonomous region in Western China). I thought about how the university had cultivated me for four years and how I had a good record in various areas, including politics. It would not be good if I refused to go to Xinjiang at that time ... Therefore, I gave up a job offer and went to Xinjiang.(February 15, 2007)

Actually, both the officials and the volunteers admitted that compulsory volunteer participation is prevalent in China. For example, officer-1 of the CYL, who was responsible for coordinating and mobilizing voluntary services in Shandong Province, also admitted that sometimes, government-organized volunteering was mandatory. He said:

Now, all youth volunteer activities in China are governed by the Central Committee of the CYL. The Central Committee issues announcements and sends them to our province, and then we send the announcements to the CYL at the city level, and from the city to the district level, step by step, from the central to the local levels...Our governmental institutions initiate [the work] as usual, asking people to clean the streets, to visit elderly people. (February 12, 2007)

Moreover, the latest official documents The Implication Plan of Establishing Jinan a National Civilized City (2013-2014) (Committee for the Building of Spiritual 
Civilization of Jinan, March 19, 2013) set the goals of promoting volunteerism as follows: "more than 90\% citizens should support the voluntary activities" (p. 23) and "the participation rate of tree planting and green-protecting should reach to 70\%” (p. 24). Under such circumstance, the party members and CYL members were asked to be volunteers. For instance, Officer-3, an officer of a street office (jiedao banshichu), described in an email,

I am also a "volunteer" now. I have to do some cleaning as early as six every morning...We are the most grass-roots level of government. We have to support the upper level government. It will incur deductions on our salary if we refuse to do the "voluntary work."(May 14, 2013)

\section{Spontaneous participation in volunteering}

Apart from this top-to-bottom compulsory volunteering model, there is also a bottomup spontaneous volunteering participation model, which is very similar to the structure of volunteer participation in the West. In the study, the participation of 17 volunteers' met this definition (i.e., spontaneous participation). They informed that their volunteer participation was a personal choice and they have gained psychological satisfaction from the volunteering experience. With little doubt, the bottom-up, spontaneous volunteers are driven by both egoistic (e.g., psychological satisfaction) and altruistic motives (e.g., helping people in need or promoting the welfare of society as a whole) (Gaskin and Smith 1995). Just as Organizer-F, the administrator who was also one of the founders of VSO-F, claimed:

Volunteering is a lifestyle for many people.... Volunteering for them is a path to self-actualization, it is spiritually, it is a personal choice. People are not asked to be noble...They join volunteering because they like it, or the service is in line with their interests (Dec. 19, 2006)... We won't force anybody to do a service they do not want to do ... (February 12, 2007)

Likewise, the volunteers for VSO-F expressed:

Mr. Zhu: Voluntary service should be based on free will. It is not to get money...I am willing to help others...It also proves that I have the ability to help others. (December 21, 2006)

Ms. Liu: I enrich my spare time through volunteering. I am very happy. Volunteering provides me an opportunity to obtain self-fulfillment. (December 22, 2006)

In addition, three volunteers and the administrator of VSO-E also mentioned the social need for volunteering services. VSO-E is a typical, community-based voluntary association that is spontaneously organized by residents to address various social problems. Most of VSO-E's volunteers are retired individuals or laid-off workers from state-owned enterprises. Along with market-oriented 
economic reform, the old "unit-based" (danwei zhi) welfare system - the unit (e.g., the State-owned-enterprise and various institutions) responsible for employees' welfare from birth to the grave - was abolished. The new social security system, however, has not been fully set up. As a result, no one is directly responsible for serving unit-based communities once the "units" have given up their responsibility. Thus, there is a need for people in the same neighborhood community to organize themselves to deal with community needs and problems. One of VSO-E's founders, Organizer-E, described the reasons behind the formation of the organization:

In the days when our dorm-yard belonged to our unit, there was a gatekeeper who was paid by our enterprise. After the reforms, the unit fired the gatekeeper and a thief came to our yard...Thus, we voluntarily organized ourselves to serve as gatekeepers for security... About 20 volunteers take turns to serve about 100 families of our yard from then on. (December 14, 2006)

\section{The volunteering experience: rewarding and non-rewarding}

According to the data from the seven female and 13 male volunteers, there are no gender differences regarding the levels of satisfaction. However, volunteer satisfaction is highly related to the types of volunteering (i.e., compulsory or spontaneous): the volunteers who participated in bottom-up spontaneous volunteering generally felt happier than those who participated in top-to-bottom compulsory volunteering.

\section{Rewarding volunteering experiences: happiness in helping others and in gaining self-development}

All of the volunteers who participated in bottom-up spontaneous voluntary service felt that the volunteering process was rewarding. Much like volunteers in the West, the spontaneous volunteers regarded their services as beneficial - both in helping others and in achieving self-development (Youniss, Yates, and $\mathrm{Su}$ 1997). For example, Organizer-E, a retired woman, said:

I feel doing good deeds [is] better than eating healthy food. When the people are happy because of my help, I feel that I am happier than them. I think the meaning of life is helping others. (February 15, 2007) 
Miss Li, a VSO-D volunteer, also opined:

In addition to gaining knowledge that we cannot learn from textbooks, I feel happy when I am serving others. I am happy even though I don’t get anything. (December 30, 2006)

Moreover, many volunteers claimed that they had improved their communication and management skills through volunteering. For example, Miss Tian, a leader of VSO-F's service group stated:

Several years ago, I never spoke to strangers...Since I joined VSO-F, I found that my communication skills have improved...I learnt much through volunteering...To put it plainly, I never knew how to organize a team before I joined and served as a volunteer. (December 23, 2006)

Mr. Su, a postgraduate student who volunteered through VSO-D, also greatly valued his volunteering experience:

I gained a lot of valuable experience. Firstly, I learnt the operations of a small organization, including organizational cooperation skills and the common rules, for example, the constitution, financial regulations, project regulations and the secretariat and personnel structure...I felt that I grew up through my service with VSO-D. (December 30, 2006)

\section{Non-rewarding volunteering experiences: service failure and poor management}

According to the volunteers who participated in the government-organized GVWC project, the top-to-bottom volunteering was poorly managed and did not meet social needs. These volunteers felt that they were wasting their time while volunteering for the project. For instance, Ms. Sun, a GVWC volunteer who participated in the project in 2003 and became a primary school teacher after she returned to Jinan, complained:

When I signed the service contract, I did not know where I would go to carry out service, and I didn't know what I will do. They changed the assignment several times... When we arrived there, we hoped that we could express our opinions about the volunteering program, but we did not have such an opportunity ... The four ministries of this program were not well coordinated. Each ministry said that you should contact another ministry...

Maybe the intentions of the volunteering program are nice. However, the fact is that the local government does not know what we can do for them. Some volunteers who majored in computer science were assigned to the areas that actually do not have any computers. It was clear that these volunteers could not use their computer skills in the areas without computers at all...As a kind of government-organized voluntary activity it is propagandistically effective, but its effect is very little. I think the contribution of volunteering is quite limited. (February 20, 2007) 
Similarly Mr. Yang, a graduate student who volunteered through the GVWC project in 2005, was also dissatisfied with his volunteering experience:

The volunteering experience is not important. Even if I didn't participate in the GVWC project as a volunteer, I would have had another work experience somewhere else...Maybe it was helpful to me to adapt to society. However, I don't think that volunteers can help society much. (February 16, 2007)

Moreover, Mr. Yang, who has often served in both quasi-governmental organization VSO-B and the grassroots organization VSO-C, told us that he has more than 6 years' volunteering experiences, yet his volunteer experience in VSO-B was non-rewarding, since the management is poor. Thus, he prefers to volunteer in VSO-C, because VSO-C's management is much better than VSO-B. He explained the story as follows:

They (VSO-B) planted trees, yet [did] not [take] care of the trees. About $80 \%$ of the trees were dead...VSO-C's activities are much better than VSO-B. Before planting the trees, VSO$\mathrm{C}$ will choose the right place for planting and take good care of the trees after the trees are planted (December 31, 2006)... I think that VSO-B depends on the government, because its president is the retired governor... I would not donate to them again since their management is poor. And I seldom participate in the activities organized by VSO-B now, but I will continue to volunteer in VSO-C. (February 10, 2007)

\section{Possible impacts of volunteer experience: the participants' attitudes toward volunteering and civil society}

Given the relatively long time period of participation, the volunteers have had (i.e., $40 \%$ of them have volunteered for more than 4 years, $80 \%$ has volunteered for more than 2 years, and 100\% has volunteered for more than 1 year) (see Table 2 in Appendix), this study also explores how the VSO's characteristics and management styles shape the volunteers' service experiences and attitudes toward the act of volunteering and the future development of civil society in China. The findings illustrate that the participants' volunteering experiences have elicited the following general attitudes toward volunteering and the development of civil society in China: (1) Positive - volunteers who have successful volunteer-participation experiences not only devote themselves to volunteering, they also believe that their service contributes to the development of civil society by advocating for institutional change; (2) Enthusiastic - volunteers with this attitude enjoy volunteering but do not care about the development of civil society; and (3) Pessimistic - this type of volunteer thinks that volunteering cannot contribute to the creation of a civil society. 


\section{Positive attitudes on both volunteering and civil society}

Both the organizers and the volunteers from the bottom-up, issue-based VSOs (i.e., VSO-C and VSO-D) were confident in their attitudes toward the development of volunteering and civil society in China. For instance, Organizer-C and Organizer-D, the founders of VSO-C and VSO-D, respectively, had a clear vision of how a civil society might be achieved. They not only actively promoted voluntary service projects but also made conscious efforts to promote institutional change by advocating law reform to create a civil society. For example, Organizer-C often wrote letters to the relevant officials to suggest changes to the policies on volunteering and environmental protection. He believes in volunteering from a civil rights perspective and questioned the operability and legitimacy of the existing environmental laws. Even though his suggestions were seldom accepted by the authorities in Jinan, he felt confident in his organization and the development of civil society. He said:

In my opinion, voluntary service is the right to know, the right to participate, and the efforts to care for vulnerable groups in society. Voluntary service will enhance public participation on public policy...(Dec. 16, 2006)...Even though sometimes the governor doesn't understand or would not support our advocates and services, we...work for a better environment, not for ourselves. If we cannot conduct the activities in Jinan one day, we can continue our work and get understanding and support in other places, for example, Maguan county of Yunnan Province. (July 24, 2012)

The VSO-D's founder and the volunteers were also confident that they were fostering civil society values such as democracy, equality, and participation through their service. They said:

Organizer-D: I grew up in Hong Kong. As an intellectual, I feel responsibility to my country...As I gain a better understanding of China, I'd like to do something to promote the development of civil society inside China rather than advocate it outside...I found a student association in the social work department. I am hoping and waiting for a policy change in the country. (April 3, 2007; see also Xu and Ngai 2011, 255)

Volunteer-Miss Li: [Civil society] is democracy, equality and full participation... Volunteering is a process of public participation. Volunteering may promote progress with policies and reform. It will definitely contribute to the development of democracy. (December 23, 2006; see also Xu and Ngai 2011, 255)

Volunteer-Mr. Su: Civil society means democracy and participation. The work we are doing is from the bottom up. It is a sort of democratic representation. And we are involved [in civil society]. (December 23, 2006; see also Xu and Ngai 2011, 255) 


\section{Enthusiastic attitudes on volunteering with indifferent attitudes toward civil society}

The volunteers from VSO-E and VSO-F manifested a strong enthusiasm for volunteering. However, they were indifferent to the development of civil society. As previously mentioned, the VSO-E volunteers were largely retired individuals and laid-off workers from a state-owned enterprise who were once part of the ruling class in the early days of socialist China. They organized themselves spontaneously to improve the quality of living at the community level, but they were pessimistic about the volunteers' contribution to the development of civil society. For example, Organizer-E said:

I only want to serve our community. I don't think the voluntary services will contribute to the development of civil society...The officials can do anything they want...Maybe just a few officials are extremely corrupt. However, many officials are grey (lack integrity)...Social harmony can be achieved only if the leaders make an effort. (December 14, 2006)

Moreover, though some of the VSO-F volunteers also enjoyed participating in voluntary service, they were not concerned about the development of civil society. Unlike Organizer-E, who felt upset because she could not reverse the decline in her income and living conditions that occurred after marketoriented economic reform, the VSO-F volunteers were satisfied with their lives and did not want to pursue social change. They only regarded volunteering as a personal choice that contributed to their happiness or selfdevelopment, allowing them to improve their quality of life. Ms. Liu, a VSO-F volunteer, explained:

I don't have a clear idea about civil society. Now, I am very satisfied with my life and I am very happy. I have become a senior nurse, and I am only at middle age...I feel happy that I can enrich my spare time by participating in volunteering through VSO-F. (December 22, 2006)

Although both Ms. Liu and Miss Tian seemed indifferent to the pursuit of a civil society, they both sought to experience autonomy and self-governance as part of their voluntary service. Because self-governance is actually an important element of civil society (Taylor 1995), their actions actually embody the value and spirit of a civil society. In fact, in the interview, Ms. Liu offered suggestions for expanding autonomy in volunteering. She said:

I think that VSO-F is just at its infancy. In the future, I suggest that volunteers be involved in the management. In other words, volunteers may organize activities by themselves. Thus, we can organize service by ourselves and reduce the VSO-F workload. (December 22, 2006) 
In fact, some VSO-F volunteers had set up and managed a Bulletin Board System (BBS) and eight QQ (a real-time chat program) groups that allowed Web users to get service information and register and discuss services via the Internet. Interestingly, seven sub-groups of the VSO-F used the BBS to offer services every Sunday. Miss Tian, the VSO-F volunteer who said that she did not care about civil society, is a group leader who organizes weekly voluntary service opportunities via the BBS. Clearly, the enthusiasm generated by volunteering helps people achieve the autonomy to create public spheres that support the exchange of ideas regarding the management, administration, and development of volunteering services.

\section{Pessimistic attitudes toward both volunteering and civil society}

The GVWC volunteers from VSO-A were unhappy with the way the project was managed and felt that volunteering made little contribution to the development of civil society or policy change. Mr. Chen, currently a civil servant who once volunteered in Xinjiang for a year, said:

When I recalled the experience in Xinjiang, I felt sad. It seems the work was a holdover from the days when China had a planned economic system that just worked to complete a target, not for the people...Some volunteers have remained unemployed since they came back...The four departments asked us to volunteer in Western China to ease unemployment pressure on university students. This is not a long-term solution. We feel hurt. We feel we have been cheated...Civil society, I think, is just a sales pitch! Voluntary service is nasty...I did not consider...volunteering after I came back from Xinjiang. (February 15, 2007)

Ms. Sun, the volunteer who joined the GVWC project in 2003, also noted the limitations of volunteers' influence on policy change:

I felt that the capacity of the voluntary services was quite limited. I hoped to offer my suggestions, but there were no channels that let me communicate to the relevant departments...I hoped to offer my services, but there were no places that let me do that... Volunteering cannot contribute at the policy level. (February 20, 2007)

This view was reinforced by another GVWC volunteer, Mr. Yang. He commented on the social constraints impeding the development of civil society in China:

There are few grassroots voluntary associations in China...In my opinion, there will be a very long, very difficult road ahead if we expect Chinese voluntary services to be as effective as in Western countries. Frankly speaking, under one-party dictatorship, the CCP might feel threatened if the voluntary services are too influential... (February 16, 2007) 


\section{Discussion and implications}

This study aims to provide a systematic understanding of Chinese volunteers' motives for volunteer participation and how the differed voluntary service experiences affect their attitudes toward volunteering and the future development of civil society. The findings illustrate the following: first, spontaneous participants with rewarding experiences who volunteer through grassroots, issue-based VSOs are most likely to have a positive attitude toward volunteering and believe that volunteering can make contributions to the development of civil society. Second, participants in grassroots and community-based VSOs are most likely to have an enthusiastic attitude toward volunteering, but they tend to be indifferent about the idea of civil society. However, they do tend to contribute to the development of volunteering and civil society when given the opportunity, because participation in voluntary services enhances their participatory abilities and their sense of self-organization and mutual collaboration. Last but not least, volunteers who participate in a poorly managed volunteering organization and have a dissatisfactory, non-rewarding volunteering experience are most likely to have a pessimistic attitude toward volunteering and civil society. Thus, there are multiple possibilities for volunteers to be involved in promoting the development of civil society. The key issue is whether the voluntary activities can facilitate the positive engagement of the volunteers. These details help inform the relationship between volunteering and civil society in China and simultaneously elicit new insights into the implications of the development of volunteering and civil society.

\section{The top-to-bottom, compulsory volunteer participation and the civil society}

The compulsory volunteer participation often occurs in top-to-bottom volunteering, which is normally organized by relatively formal, larger institutions. Bottom-up volunteering is often initiated by relatively informal and smaller grassroots organizations. It is not uncommon that both top-to-bottom and bottom-up volunteering can be found elsewhere outside China, yet the uniqueness displayed by the top-to-bottom volunteering lies in the knowledge that the Chinese government or quasi-governmental organizations usually take the leadership roles that might otherwise belong to the service organizer (Xu 2012a). Therefore, it is worth addressing a unique question in the Chinese context: can government-led volunteering be defined as a part of civil society? 
The findings reveal that it is not the organizers' political background but the VSOs' characteristics and management styles that ultimately shape a volunteer's experience, which significantly affects a volunteer's willingness to promote the development of civil society. Yet, the compulsory volunteer participation, which was often led by the government, can hardly be defined as a part of civil society. Given the fact that China is a one-party state with a centralized power system, sometimes the organizer may exercise the power to ask some people (e.g., Communist Party Members) to be "volunteers." As a result, at the macro-ideological level, there is little room for the compulsory volunteering to develop the basic values of a civil society such as altruism, democracy, and autonomy. At the meso-institutional level, the Chinese government or quasi-governmental organizations usually direct the compulsory volunteer programs, which do not meet with the requirements of a civil society in which there is a self-organizing or self-coordinating space, which is not dominated by state power (Taylor 1995). At the micro-individual level, the compulsory volunteering could hardly foster a sense of civil society, since it is likely to result in those volunteers feeling as if they volunteered under pressure.

Moreover, volunteers who participate in a poorly managed volunteering project and have a non-rewarding or even dissatisfactory volunteering experience are most likely to be pessimistic toward both volunteering and the development of civil society. This finding echoes previous research that supports the belief that the environment of the organization has a significant impact on volunteer motivation and ability (Tan 2001; Wang 2003; Milligan and Fyfe 2005; Brudney and Meijs 2009). For example, the VSO-A's volunteers' experience has served as a cautionary tale of the extreme results that can occur in mandatory volunteering: if the compulsory volunteer project is poorly managed, the dissatisfactory volunteering experience may not only upset the volunteers but also produce a negative effect on the government's credit in volunteering as well as the political realm.

Furthermore, it is worthy to be noted that the government-organized volunteering activities are not bound to take the form of compulsory participation or to be poorly managed. For example, quasi-governmental, environmental VSO-B allowed the volunteers to spontaneously join or leave the organization. One of the four volunteers we interviewed has withdrawn from the organization (Interview: VSO-B \& C-Mr. Yang, February 10, 2007), and the other three volunteers did not rely on VSO-B but sometimes organized environmental activities by themselves (Interview: VSO-B - Mr. Ma; VSO-B - Mr. Qu; VSO-B - Mr. Wang, January 4, 2007).

Therefore, based on the findings we discussed above, implications for improving the management of the top-to-bottom volunteer programs can be generated as follows: 
(1) Matching volunteers' skills and experience with appropriate assignments. Screening and matching the volunteers to the appropriate tasks may enhance the satisfaction of the volunteering experience and improve the retention of the volunteers (Hager and Brudney 2008; Eisner et al. 2009). Unfortunately, however, it was found that volunteers were often assigned to do jobs un-related to their skills in the top-to-bottom volunteer programs in China. For example, 85.37\% GVWC volunteers were assigned to do jobs unrelated to their major (Xue, Jia, and Fang 2010), and 63.7\% volunteers were disappointed since they thought that the work places where they served actually did not need them (Yv and Ma 2010).

(2) Reducing bureaucratic barriers to improve the communication between the volunteers and the organization. As elsewhere, if an organization is too bureaucratic to allow for effective communication, the volunteers find themselves in an unpleasantly passive position (Milligan and Fyfe 2005). They easily lose heart, and their confidence in the service organizer (i.e., the government) decreases (Hustinx 2010). Therefore, the governmentbased organizations must be refined and improved by providing sufficient communication channels for volunteers to express their views, making sure that volunteers feel needed, respected, and valued. To date, new technologies allow the organizers or administrators to remove the bureaucratic barriers and communicate with volunteers conveniently and economically. In other words, to reduce this possible negative impact on governance, the structural and administrative weaknesses that lead to negative volunteering experiences should be reduced as much as possible. This would foster in volunteers a sense of active and positive civic-mindedness, a selfconsciousness that might instill in them the capacity to be responsible citizens who promote the development of civil society in particular social/ historical contexts (Habermas 1989).

\section{The bottom-up, spontaneous volunteer participation and the development of civil society}

The findings reveal that, generally, volunteers who participated in bottom-up spontaneous volunteering were more likely to have a rewarding service experience than those who participated in top-to-bottom compulsory volunteering. This was because the grassroots VSOs did not have the kind of power exercised by government authorities to require people to support and participate in volunteer activities. In other words, the bottom-up service organizer can only use its virtue to entice people to participate (Habermas 1989). In addition, 
spontaneous volunteers may withdraw their participation if they regard their service experience as non-rewarding.

Normally, an individual who participates spontaneously in volunteering is making a personal choice regardless of whether they join an issue-based VSO or a community-based VSO. Yet, evidence showed, for one thing, individuals who volunteer through a grassroots, issue-based VSO (especially those VSOs that include promoting civil society as one of its missions) are most likely to think and act positively regarding both volunteering and civil society. With little doubt, when volunteers choose a VSO and participate in its specific voluntary activities, it means that they also support the VSO's mission and values (Xu and Ngai 2011). The volunteers who continue to stay in an issue-based VSO not only report relatively pleasant service experiences but also agree with the VSO's mission (Hustinx 2010; Taniguchi 2010). Therefore, if volunteers choose a grassroots VSO with a clear mission to promote the development of civil society, their service will be more likely to influence social policy for the public good and consciously promote the development of civil society (Fisher 1998).

For another thing, the volunteers who participate in grassroots, communitybased VSOs are most likely to be enthusiastic volunteers even if they are indifferent toward the concept of civil society. Usually, the membership of a community-based VSO is restricted to the local geographic area, and its volunteers will emphasize their interest in the community over the promotion of institutional change or the development of civil society (Pickert 2003; Wagner 2004). Because these volunteers come from a relatively small and confined local area with a shared culture, they are typically able to organize themselves, enjoy autonomy in their service, and quickly respond to community needs (Putnam 1995). According to Taylor (1995), a civil society exists if "there are free associations that are not under tutelage of state power” (p. 208). Therefore, these volunteers who have pursued and enjoyed autonomy in their service also foster minimal civil society "whereby engagement in the accepted dimensions of associational life generates the habits, practices, and values that contribute to the growth of civil society as a whole" (Watson 2008, 47), even if they do not intend to do so.

In addition, it is worthy to point out, though the development of grassroots NGOs is being constrained to some extent as the party-state wants to maintain political stability (Ma 2002; Qi 2004; Cooper 2006), that the grassroots VSOs are not willing to confront the State. On the contrary, the VSOs expect to get the government's understanding and support. For example, the administrator of VSO-C Organizer-C said, "I have many suggestions about voluntary service and environmental protection. However, the government doesn't give me the opportunity to express my views” (December 16, 2006; see also Xu and Ngai 2011, 257). 
Mr. Li, a volunteer from the grassroots environmental VSO-C, also explained, "I expect that the government can give more support to us. And I hope a better understanding could be built between the government and us" (December 20, 2006). Thus, specifically, the policy implications of the development of bottomup volunteering and civil society can be generated as follows:

(1) Promote better communication channels between the government and the grassroots, issue-based VSOs. With growing economic and social freedom since the late 1970s, the Chinese government has cautiously welcomed VSOs to play an increasingly important role in the welfare provision. In this study, most of the volunteers are well-educated individuals with regular jobs who were satisfied with their current incomes. Eighty percent of the interviewees had a college diploma or above. With little doubt, the majority of the spontaneous participants of the issue-based VSOs are professionals or middle class with specific skills. There is much to be gained if participants of those relevant VSOs will be consulted during the policy-making process.

(2) Provide financial support to the grassroots, community-based VSOs. Since the grassroots, community-based VSOs may know their communities' needs, as well as the underlying challenges, better than any outsiders, the government will benefit much by funding certain grassroots, community-based VSOs to conduct the service projects, in contrast to taking the welfare burden themselves (Xu 2012b).

\section{Limitations and further research}

As an exploratory study, this study has limitations, and it raises many interesting questions that require further research. A major limitation lies in the current availability of the sample. First, because there is no complete record of either the volunteers or the VSOs in China, random sampling is impossible. Though a lot of valuable first-hand information was collected, the findings were based on nonrandom, relatively small-sized samples, and thus the representativeness of this study could be challenged.

Second, given the fact that China is in a period of transition, further researches should be conducted in the near future. For example, the GVWC project has been launched for 10 years (i.e., 2003-2012). The project will continue in a more competitive environment because of the recent creation of similar government-organized projects. As Mr. Zhu, the director of Department of Youth Volunteer Work of the Central CYL, pointed out, "Today, we are facing 
challenges. For instance, the Program of Graduate Village Leader (Daxuesheng Cunguan) organized by the Ministry of Human Resources and Social Security of China, or the Special Teacher (Tegang Jiaoshi) organized by the Ministry of Education, also recruit graduates every year. And the paid allowances of these new programs are much higher than the GVWC project" (Interview: July 11, 2012). What's the difference between these similar programs? Do these government-organized service programs have similar strengths and weaknesses? Moreover, if we refer to a broader global vision, questions arise as to why the state-led volunteering programs exist in both authoritarian and democratic regimes. An example for the latter is the AmeriCorps, which aims to expand opportunities for Americans of all ages to serve their communities (Gerdes 2011). Thus, it seems that all the state-led programs have similar goals in encouraging people to serve their country and promoting the core values of a certain nation. Yet, can the state-led volunteering programs be the panacea that advances the very different values of different states? In a word, many such deeper questions remain unknown and more studies are needed.

In addition, this study has illustrated a wide age distribution (between 20 and 68) of the volunteer participants, and more than $80 \%$ of them had a college diploma or above. However, the relatively small sample size limits further analyzing the interesting questions such as: To what extent is volunteer participation related to the emerging middle-class social status in China? Does being in the middle class, such as having a stable retirement pension for recent retirees, or having dual-income urban parents as college graduates correlate with their volunteering participation and thus volunteering satisfaction, and eventually, civil consciousness? In certain types of volunteering activities, such as maintaining security for the local community, do men feel more rewarded than women? In short, to further explore the variation of social class or gender differences in volunteer participation, the future researchers may narrow down the research question and choose a relatively large volunteer program, which has a complete population, to perform random sampling, and use inferential statistics to make inferences in the data analysis. And the sociological perspectives such as the social class theory, demographic, or life-course perspective may provide insights into the volunteers' motivations and satisfactions of their volunteer activities. Thus, we may get more specific knowledge of the volunteer participation rather than a comprehensive understanding of the development of the civil society of China. 


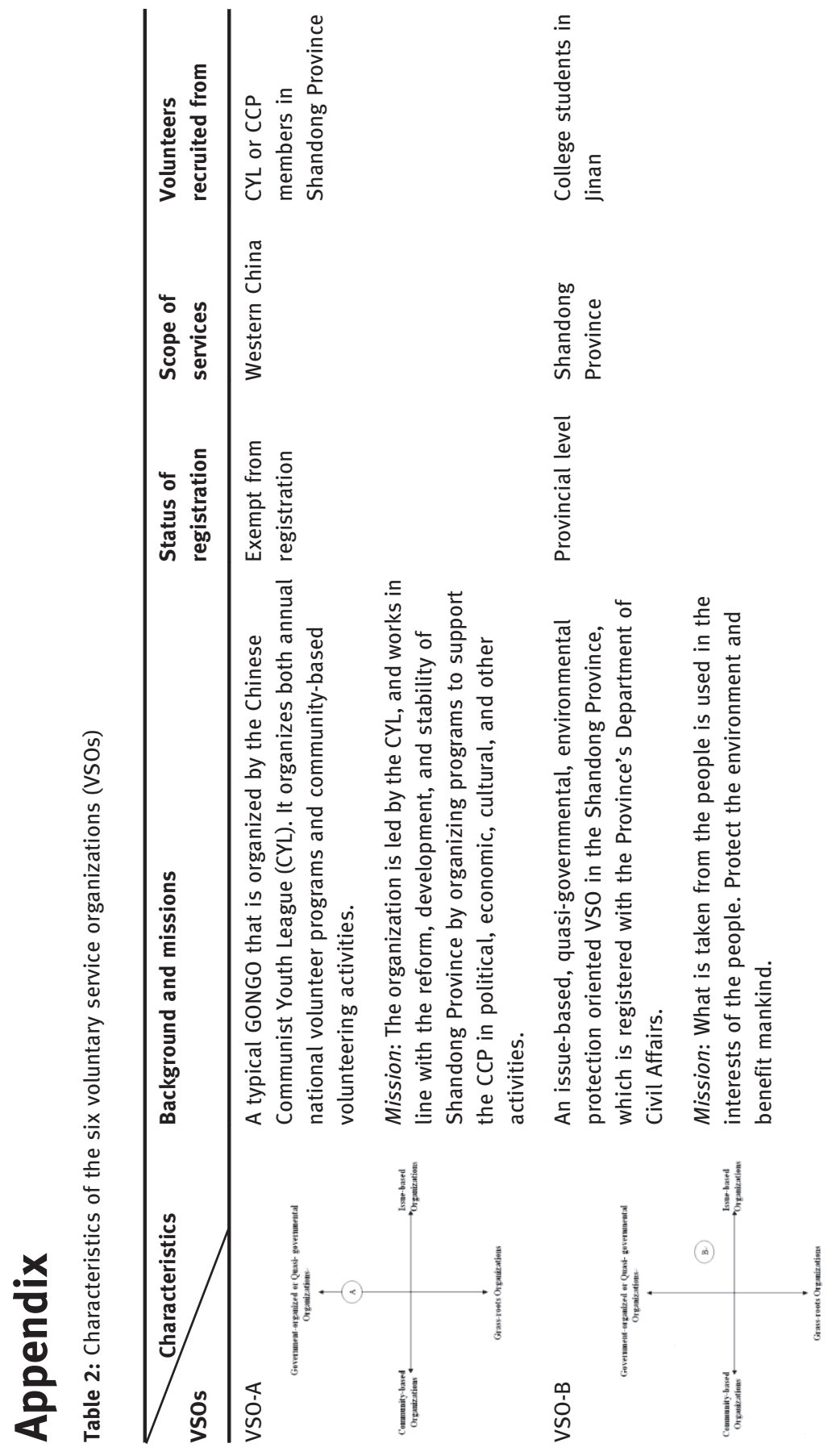



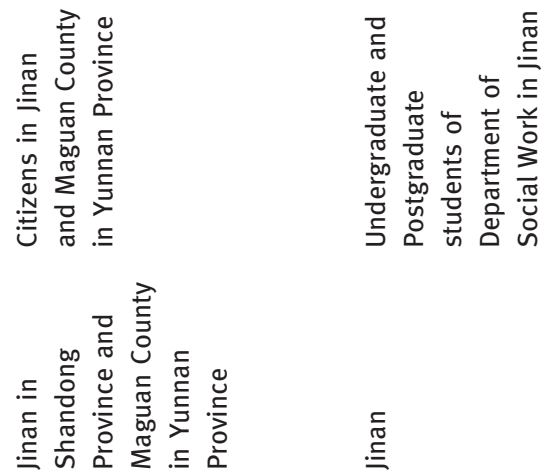

$\stackrel{\text { స్ }}{.}$

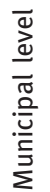
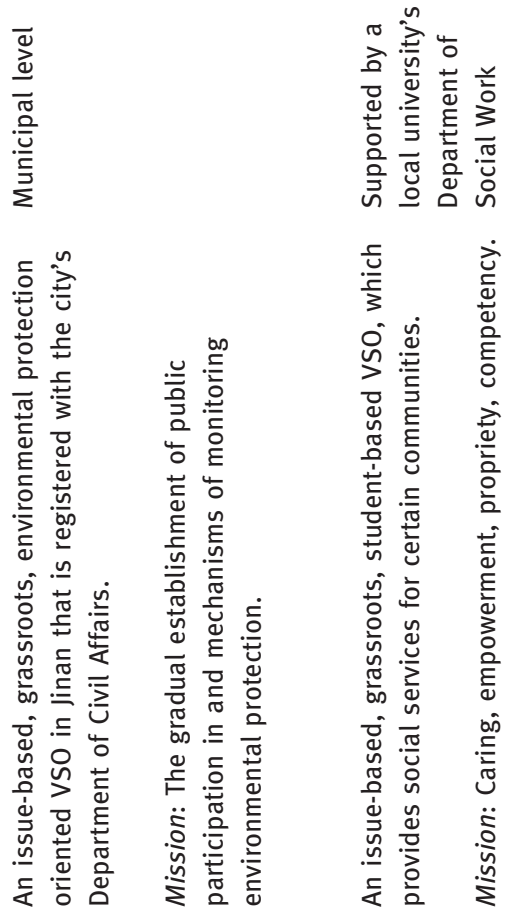

$\frac{\text { 는 }}{3}$

กั่

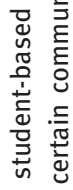

जั

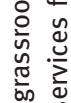

iृ $\frac{\pi}{.0}$

空

जู 包

뜨를


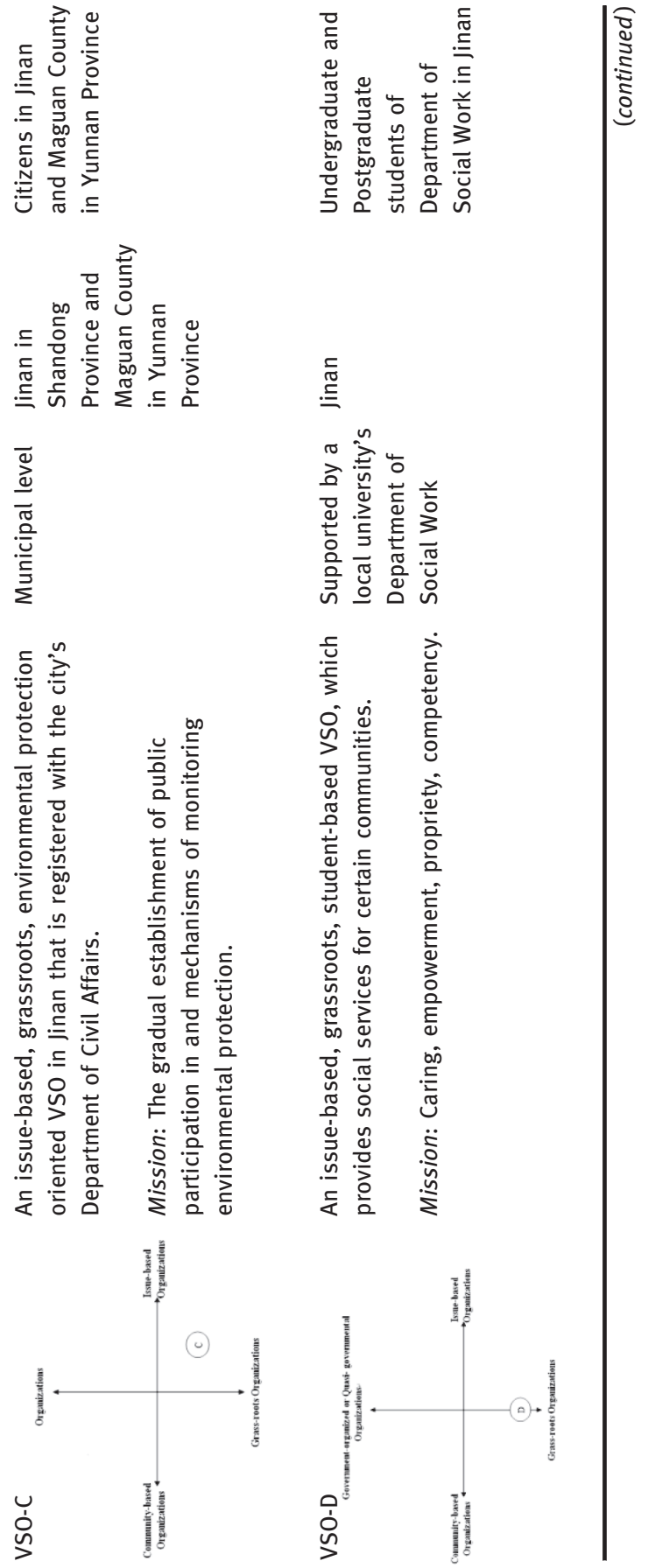


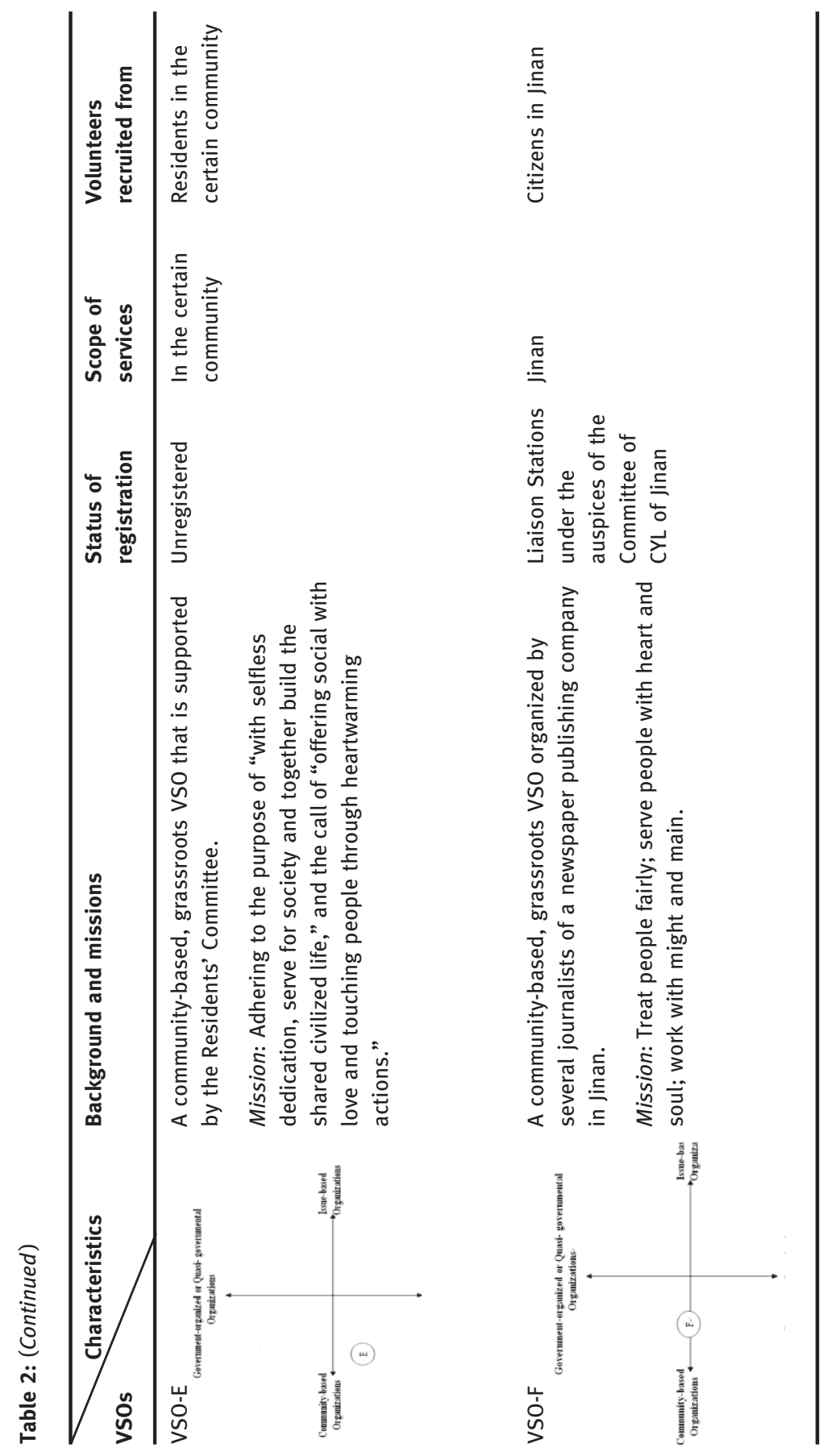




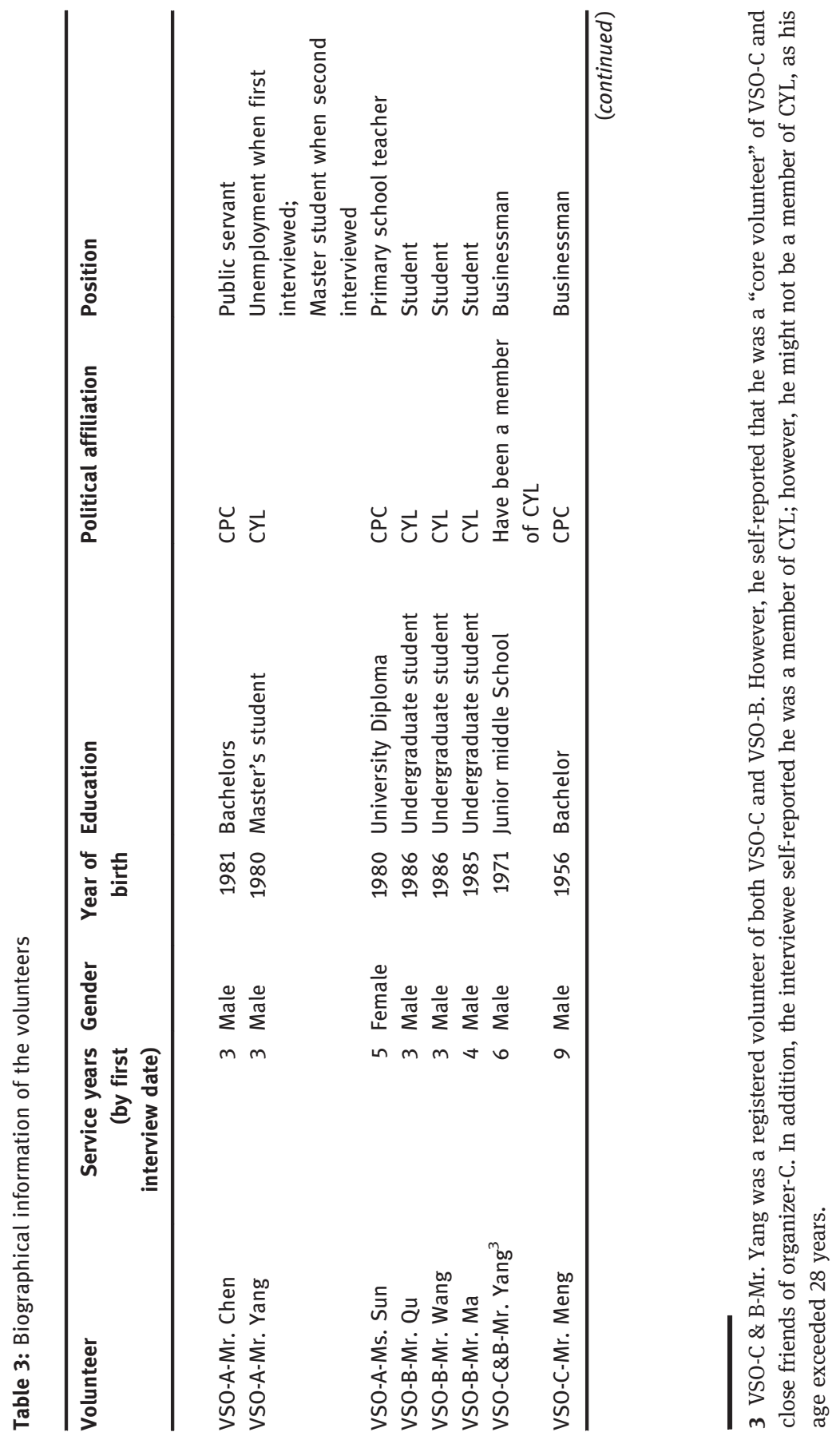







Acknowledgments: I acknowledge the funding support of the 'Direct Grant for Research' from the Social Science Panel of The Chinese University of Hong Kong (code number: 2021119) and express my sincere gratitude to Professor Ngan-pun NGAI for his invaluable comments and the interviewees for their time. Special thanks also go to the anonymous reviewers and the editor for their critical and constructive comments.

\section{References}

Adams, M. 2006. "Hybridizing Habitus and Reflexivity: Towards an Understanding of Contemporary Identity?" Sociology 40(3):511-28.

Anheier, H. K., and L. M. Salamon. 1999. "Volunteering in Cross-National Perspective: Initial Comparisons." Law and Contemporary Problems 62(4):43-65.

Anheier, H. K. 2004. Civil society: measurement, evaluation, policy, London; Sterling, VA: Earthscan Publications.

Arendt, H. 1958. The Human Condition. Chicago and London: The University of Chicago Press.

Barber, B. R. 1998. A Place for Us: How to Make Society Civil and Democracy Strong. New York: Hill and Wang.

Bekkers, R. 2008. "Volunteerism." In International Encyclopedia of the Social Sciences, edited by W. A. Darity Jr.,641-3, 2nd edn. Detroit: Macmillan Reference USA.

Brudney, J. L., and L. C. P. M. Meijs. 2009. “It Ain’t Natural: Toward a New (Natural) Resource Conceptualization for Volunteer Management.” Nonprofit and Voluntary Sector Quarterly 38(4):564-82.

Cheung, C. K., and N. P. Ngai. 2004. "Humanist Approaches to Youth Development in the Summer Youth Program of Hong Kong." Journal of Social Service Research 31(2):1-24.

Cnaan, R. A., H. Femida, and W. Margaret. 1996. "Defining Who Is a Volunteer: Conceptual and Empirical Consideration.” Nonprofit and Voluntary Sector Quarterly 25(3):364-83.

Cohen, J., and A. Arato. 1992. Civil Society and Political Theory. Cambridge, MA: MIT Press.

Committee for the Building of Spiritual Civilization of Jinan. 2013. "The Implication Plan of Establishing Jinan a National Civilized City (2013-2014). (in Chinese)[Jinanshi chuanjian quanguo wenming chengshi shishi fangan(1013-2014)]". Accessed May 14, 2014. http:// www.jngy.gov.cn/temp/editer/1367190285781.doc

Cooper, C. M. 2006. "This Is Our Way in: The Civil Society of Environmental NGOs in South-West China." Government and Opposition 41(1):109-36.

Deng, Z. L., and Y. J. Jing. 1992. "Jiangou Zhouguo De Shiminshehui (in Chinese) [Building Civil Society in China]." Chinese Social Science Quarterly 1:58-68.

Dunn, P. C. 1995. "Volunteer Management." In Encyclopedia of Social Work, edited by Edwards, R. L. \& Hopps, J. G., Vol. 19, 2483-90. New York: National Association of Social Work.

Eisner, D., R. T. Grimm, S. Maynard, and S. Washburn. 2009. The New Volunteer Workforce, Stanford Social Innovation Review, Winter 2009. Accessed August 10, 2012. http://www. ssireview.org/pdf/the_new_volunteer_workforce

Ellis, S. J. 1986. From the Top Down: The Executive Role in Volunteer Program Success. Philadelphia, PA: Energize Associates. 
Fisher, J. 1998. Nongovernments: NGOs and the Political Development of the Third World. West Hartford, СT: Kumarian Press.

Gaskin, K., and J. Simth. 1995. A New Civic Europe? A Study of the Extent and Role of Volunteering. London: The Volunteer Centre UK.

Geller, E. 1996. Conditions of Liberty: Civil Society and Its Rivals. London: Penguin Books.

Gerdes, L. I. 2011. “Introduction.” In National Service, edited by L. I. Gerdes, 14-20. Detroit: Greenhaven Press.

Habermas, J. 1989. The Structural Transformation of the Public Sphere. Translated by Thomas Burger with the assistance of Frederick Lawrence. Cambridge, MA: MIT Press.

Hager, M. A., and J. L. Brudney. 2008. "Management Capacity and Retention of Volunteers." In Challenges in Volunteer Management, edited by M. Liao-Troth, 9-27. Charlotte, NC: Information Age Publishing.

Heiderich, K. W. 1991. Working with Volunteers in Employee Services and Recreation Programs. Champaign, IL: Sagamore Publish, Inc.

Heinrich, F. V. 2004. Assessing and strengthening civil society worldwide. Retrieved September 2, 2010 from <http://www.civicus.org/new/media/CSIAssessingnandStrengtheningCivil SocietyWorldwide.pdf>

Hustinx, L. 2010. "I Quit, Therefore I Am? Volunteer Turnover and the Politics of SelfActualization." Nonprofit and Voluntary Sector Quarterly 39(2):236-55.

IAVE. 2001. "The Universal Declaration of Volunteering." Accessed March 13, 2006. http://www. volunteeringaustralia.org/documents/UniversalDeclaration.pdf

Jia, X. J., and J. H. Pan. 2006. Shehui Zhuanxingqi De Zhili (in Chinese) [Governance in Social Transformation: Civil Society Index of China]. Macao: The Second in the 21st Century Public Management: Opportunities and Challenges International Symposium. Accessed November 30, 2006. http://www.umac.mo/fsh/pa/2nd_IntPAConference/ JiaXijin\&PanJianhui.doc

Jiang, Q. 1993. "Rujia Wenhua: Jiangou Zhongguoshi Shiminshehui De Shenhou Ziyuan (in Chinese) [Confucian Culture: Rich Resources of Establishing a Chinese-Style Civil Society].” Chinese Social Science Quarterly 3:170-5.

Jinan Daily. 2009. "Voluntary Service Is an Important Social Soft Power (Zhiyuan Fuwu Shi Zhongyao De Shehui Ruanshili) (in Chinese).” Accessed December 12, 2009. http://jnrb1. e23.cn/jinrb/20091209/page_10.jpg

Jinan Development and Reform Commission. 2006. "Jinan Volunteering Administration Regulations.” Accessed March 24, 2007. http://www.jndpc.gov.cn/E_ReadNews.asp? NewsID $=752$

Kennedy, S. 2008. "The Price of Competition: The Failed Government Effort to Use Associations to Organize China's Market Economy." In Associations and the Chinese State: Contested Spaces, edited by J. Unger. New York: M. E. Sharpe.

Lynd, R. S., and H. M. Lynd. 1929. Middletown: A Study in Contemporary American Culture. New York: Harcourt, Brace and Company.

Ma, Q. 2002. "The governance of NGOs in China since 1978: How much autonomy?" Nonprofit and Voluntary Sector Quarterly. San Francisco 31(3):305-328.

McCurley, S., and R. Lynch. 2006. Volunteer Management: Mobilizing All the Resources of the Community, 2nd edn. Philadelphia, PA: Energize.

McFarland, D. A., and R. J. Thomas. 2006. "Bowling Young: How Youth Voluntary Associations Influence Adult Political Participation.” American Sociological Review 71:401-25. 
Milligan, C., and N. Fyfe. 2005. "Preserving Space for Volunteers: Exploring the Links Between Voluntary Welfare Organisations, Volunteering and Citizenship." Urban Studies 42 (3):417-33.

NaKano, L. Y. 2000. "Volunteering as a Lifestyle Choice: Negotiating Self-Identities and in Japan." Ethnology 39(2):93-107.

Ngai, S. S., N. P. Ngai, C. K. Cheung, and S. M. To. 2008. "Service Participation, Hardiness and Developmental Outcomes among Low-Income Young People in Hong Kong." International Journal of Adolescence and Youth 14:185-203.

Pan, Y. 2005. "Community Volunteers Reached to 16 Million; and the Volunteering Rate in Urban Population Was Only 3\%." China Daily, December 6.

Pick, D., K. Holmes, and M. Brueckner. 2011. "Governmentalities of Volunteering: A Study of Regional Western Australia." Voluntas 22:390-408.

Pickert, M. A. 2003. "Creating Citizens: Volunteers and Civil Society, Japan in Comparative Perspective." Unpublished doctoral dissertation (AAT 3102700), University of Washington.

Putnam, R. D. 1995. “Bowling Alone: America's Declining Social Capital.” Journal of Democracy 6(1):65-78.

Qi, H. 2004. "The freedom of association and the system of non-corporate associations (in Chinese) [Jieshe ziyou yu feifaren shetuan zhidu]", Cass Journal of Foreign Law, 3:295-303.

Srinivas, N. 2009. "Against NGOs? a Critical Perspective on Nongovernmental Action." Nonprofit and Voluntary Sector Quarterly 38(4):614-26.

Tan, J. G. 2001. "Shenzhen Qingnian Zhiyuanzhe De Gean Yanjiu (in Chinese) [a Case Study of Some Young Volunteers in Shenzhen]." Journal of China Youth College for Political Sciences 20(6):52-5.

Taniguchi, H. 2010. “Who Are Volunteers in Japan?” Nonprofit and Voluntary Sector Quarterly 39 (1):161-79.

Taylor, C. 1995. Philosophical Arguments, Cambridge: Harvard University Press.

Tian, K. 2004. "Organizational Operation under Non-Coordinate Constraint: A Framework of Research on the Relationship Between the Charity Organizations and the Government in China (in Chinese)." Sociological Research 4:64-75.

Trentmann, F. 2000. Paradoxes of Civil Society: New Perspectives on Modern German and British History. New York: Berghahn Books.

Unger, J., and A. Chan. 2008. "Associations in a Bind: The Emergence of Political Corporatism." In Associations and the Chinese State: Contested Spaces, edited by J. Unger. New York: M. E. Sharpe.

U.S. Bureau of Labor Statistics. 2009. "Volunteering in the United States, 2009." Accessed September 2, 2010. http://www.bls.gov/news.release/volun.nr0.htm

Wagner, A. 2004. "Redefining Citizenship for the 21st Century: From the National Welfare State to the UN Global Compact." International Journal of Social Welfare 13(4):278-86.

Walter, P. W., and P. J. Dimaggio. 1983. "The Iron Cage Revisited: Institutional Isomorphism and Collective Rationality in Organizational Fields." American Sociological Review 48(Apr):147-60.

Wang, Q. 2003. "Zhiyuanzhe Xingdong De Sanxing Fenxi (in Chinese) [Three Basic Analyses of Young Volunteers Actions Development]." Journal of Guangdong College of Young Cadres 52(2):20-4.

Wang, M., and X. J. Jia. 2003. "Problems about Legislation for China's NGOs (Zhong Guo NGO Fa Lü Zheng Ce De Ruo Gan Wen Ti) (in Chinese)." Journal of Tsinghua University (Philosophy and Social Sciences) 18(S1):100-06. 
Watson, A. 2008. "Civil Society in a Transitional State: The Rise of Associations in China." In Associations and the Chinese State: Contested Spaces, edited by J. Unger. New York: M. E. Sharpe.

White, G., J. Howell, and X. Y. Shang. 1996. Search of Civil Society: Market Reform and Social Change in Contemporary China. Oxford: Clarendon Press.

Xu, Y. 2012a. "Chinese Communist Youth League, Political Capital, and the Legitimizing of Volunteering in China." International Journal of Adolescence and Youth. doi:10.1080/ 02673843.2012.656195. Accessed March 30, 2012. http://www.tandfonline.com/doi/abs/ 10.1080/02673843.2012.656195

Xu, Y. 2012b. "Moral Resources, Political Capital and the Development of Social Work in China: A Case Study of City J in Shandong Province." British Journal of Social Work. doi:10.1093/ bjsw/bcs070. Accessed May 29, 2012. http://bjsw.oxfordjournals.org/content/early/2012/ 05/28/bjsw.bcs070.full.pdf + html.

Xu, Y. 2012c. "Non-Governmental Organizations in China: Development and Challenges." In China: Development and Governance, edited by W. Gungwu and Z. Yongnian 311-17. Singapore: World Scientific.

Xu, Y., and N. P. Ngai. 2011. "Moral Resources and Political Capital: Theorizing the Relationship between Voluntary Service Organizations and the Development of Civil Society in China." Nonprofit and Voluntary Sector Quarterly 40(2):247-69.

Xue, Y., C. Jia, and X. Fang. 2010. "The Current Situation, Problem and Countermeasure of the Graduates Participated in the Scheme of 'Graduates Volunteering in the Western China' (Zhiyuanfuwu 'Xibujihua' Daxuesheng De Xianzhuang Wenti Yu Duice, in Chinese).” Youth Studies (Qingnian Tansuo) 1(161):54-60.

Young, D. R. 2000. “Alternative Models of Government-Nonprofit Sector Relations: Theoretical and International Perspectives." Nonprofit and Voluntary Sector Quarterly 29(1):149-72.

Youniss, J., M. Yates, and Y. Su. 1997. "Social Integration, Community Service and Marijuana Use in High School Seniors." Journal of Adolescent Research 12:245-62.

Yv, H., and Y. Ma. 2010. "Inquiry and Analysis of the Effect of Implementing Undergraduates' Voluntary Service in Western Provinces (Daxuesheng Xibu Jihua Shishi Xiaoguo Diaocha Yu Wenti Fenxi, in Chinese)." Journal of Ningbo University (Educational Science Edition) 32 (4):108-11. 